\title{
A Study on the 2018 Revised Curriculum for the Disabled and Rehabilitation Sports Instructors in Germany
}

\section{독일 장애인체육과 재활체육 지도자를 위한 2018 개정 교육과정에 대한 연구}

\author{
$\mathrm{Ho} \mathrm{Yoo}^{1}$ \\ 유호 ${ }^{1}$ \\ ${ }^{1}$ Professor, Department of Sport \& Health Management, Catholic Kwandong University, Gang \\ won-Do,Korea,yooho@cku.ac.kr
}

\begin{abstract}
The purpose of this study is to provide basic data necessary for the development of a curriculum for training instructors in rehabilitation sports in Korea. For this purpose, a comprehensive analysis of the training guidebook for the German Physical Education for the Disabled (2018), revised on July 14, 2018, and an interview with the person in charge of the German Physical Education for the Disabled were conducted. The analyzed results and suggestions derived based on this reserch are as follows. First, recently, the instructor course for disabled sports in Germany is divided into'Life Sports Instructor Course,' 'Preventive Sports Instructor Course,' 'Elite Physical Education Instructor Course,' and 'Rehabilitation Sports Instructor Course', and all educational systems are connected in a modular way. Second, the competencies required of instructors in rehabilitation sports in Germany were largely personal and social communication skills, professional skills, teaching methods and delivery capabilities. Third, it can be seen that the curriculum includes not only pedagogy and methodology subjects, but also nutrition, psychology and sociology, and observation and practice. In the case of the test, if the test was evaluated by focusing on the actual instructional ability, the license has an expiration date, and through regular retraining, it is possible to learn the latest information and to supplement and deepen the knowledge, skills and abilities learned. Fourth, it can be seen that Germany values'education as a reflective process' and 'education as a lifelong process'.
\end{abstract}

Keywords: Germany, Physical Education for the Disabled, Rehabilitation Sports, Instructor, Curriculum

요약: 본 연구는 독일장애인체육협회의 교육 지침과 재활체육 지도자 교육과정의 분석을 바탕으로 한국의 재활체육 전문 지도자 양성을 위한 교육과정 개발에 필요한 기초자료 제공을 목적으로 한다. 이를 위하여 2018년 7월 14일에 개정된 독일장애인체육협회 연수 교육 지침서(2018)의 총체적 분석, 독일장애인체육협회 웹사이트상의 다양한 자료 분석과 독일장애인체육협회의 담당자 인터뷰를 수행하였다. 분석된 결과와 이를 바탕으로 도출된 제언은 다음과 같다. 체육 지도자 과정은 ‘생활체육 지도자 과정,' ‘예방체육 지도자 과정,’ ‘엘리트 체육 지도자 과정,' 그리고 ‘재활체육 지도자 과정 ‘으로 구분되고 교육 시스템이 모듈식 구조를 갖추고 유기적으로 연계되고 있었다. 둘째, 독일의 재활체육 전문

Received: December 02, 2020; $1^{\text {st }}$ Review Result: January 18, 2021; $2^{\text {nd }}$ Review Result: March 08, 2021 Accepted: April 30, 2021 
지도자에게 요구되는 역량은 크게 개인적, 사회적 의사소통 역량, 전문적 역량, 교수 방법 및 전달 역량으로 구분되었다. 셋째, 교육과정에는 교수법이나 방법론 과목은 물론이고, 영양학이나 심리학과 사회학, 참관과 실습이 포함되어 있음을 알 수 있었다. 시험의 경우 실제 지도 수행 능력에 초점을 맞추어 진행하였으며, 라이센스는 유효기간이 있기 때문에 정기적인 재교육을 통해 최신의 정보를 배울 수 있고 배운 지식, 기술 및 능력을 보완하고 심화할 수 있도록 하였다. 넷째, 독일은 '성찰적 과정으로서의 교육' 과 '평생 과정으로서의 교육' 을 중요시함을 알 수 있었다.

핵심어: 독일, 장애인체육, 재활체육, 지도자, 교육과정

\section{1. 서론}

재활체육의 중요성을 인식하고 체계를 갖춘 독일은 2018년에 장애인체육 지도자 교육 지침을 개정하여 고도화를 진행하고 있다[1][2]. 한편, 우리나라는 현장 전문가들과 연구자들의 노력으로 인해 2017년부터 ‘장애인건강권법’ 이 제정 시행되었다. 이로 인하여 장애인들의 체육활동에 대한 요구를 충족할 수 있는 방안이 마련되고 재활체육에 대한 관심이 증가하고 있다. 그러나 재활체육 전문지도자 양성과정은 아직도 개발되지 않고 있으며, 시설과 프로그램의 개발은 여전히 부족한 현실이다. 장애인 건강권 및 의료 보장에 관한 법률 (이하 장애인건강권법)' 으로 재활체육의 활성화가 다시금 기대되고 있고, 이러한 분위기에서 장애인 체육이나 재활체육의 발전을 위해 선제적으로 이루어져야 하는 것은 전문 지도자 양성과정과 관련 프로그램의 개발일 것이다.

의료 전문 지도자 양성과정의 경우, 독일과 우리나라의 가장 큰 차이점은 우리나라에는 전문적인 재활체육 지도자 양성과정이 없다는 것이다[3]. 우리나라에서는 장애인 체육과 관련된 자격증으로는 특수학교 체육 정교사 교원자격과 장애인스포츠지도사 자격증이 있는데 이 중 장애인스포츠지도사 자격의 경우 실제로는 장애인을 대상으로 한 스포츠 종목을 가르치는 즉, 생활체육을 가르치는 전문가의 양성과정이라고 할 수 있다. 따라서 재활체육을 위한 전문가의 양성이라기에는 부족한 부분이 있다. 지금까지 전문적인 재활체육 지도자의 필요성이 제기되어왔으나 아직까지 교육과정이 만들어지지 못한 데에는 여러 가지 복합적인 이유가 있을 수 있을 것이며, 재활체육 전문지도자 교육이나 교육과정에 대한 연구가 부족한 것도 그 이유 중 하나일 수 있을 것이다.

재활체육 전문지도자 양성과 자격제도 신설, 재활체육 관련 교육을 위해서는 재활체육에 관한 제도가 체계화되고 활성화되고 있는 선진국의 사례를 참고하는 것이 필요한데, 특히 이미 재활체육에 관한 제도가 체계화되어 있는 독일의 제도를 벤치마킹 하여 우리나라에서 적용 가능한 것을 분석해 보는 것이 도움이 될 것이다.

본 연구에서는 독일의 가장 최근의 장애인 체육 교육 지침서와 재활체육 전문지도자 교육과정을 총체적으로 분석하여 우리나라의 장애인 재활체육 지도자 양성의 기본방향을 수립하고 교육과정을 개발하는 것을 목적으로 한다. 우리나라의 재활체육에서 독일의 사례를 분석한 연구는 이전에도 수행되어왔다. '한국장애인개발원' 에서 수행한 연구에서 재활체육의 개념을 정의 하고자 하였고 재활프로그램의 효과성 검증으로 
재활체육의 중요성을 강조하였다[1]. 또한 독일의 재활체육 제도를 도입하고자 시도한 ‘장애인 재활체육 발전방안' 연구도 수행되었다[2]. 이 외에 유호(2011)도 독일의 재활체육 정책과 재활체육 전문지도자 교육과정에 대한 연구를 수행하였다[3]. 그러나 이러한 선행연구들은 2017년부터 시행된 '장애인건강권법' 이 제정되기 전에 수행되어, 구체적인 방법보다는 재활체육 제도화의 필요성을 강조하고 있다. 이 외에도 독일 관련 연구들 중 2018년 개정된 자료를 바탕으로 분석을 한 연구는 찾을 수가 없다. 우리나라도 이제는 법의 제정으로 제도화는 이미 시작되었다고 할 수 있으므로 지금부터는 실행이 이루어져야 하고, 최근의 자료를 바탕으로 한 교육과정 개발에 대한 구체적인 방향이 제시되어야 할 것이다.

따라서 본 연구는 2018년 7월 14일에 개정된, 즉 최근 독일장애인체육협회의 교육 지침과 재활체육 지도자 교육과정의 분석을 바탕으로 우리나라의 재활체육 전문 지도자 양성 과정과 자격제도 신설을 위한 교육과정 개발에 필요한 부분을 도출해 내고자 한다. 본 연구에서 독일장애인체육 협회의 연수교육 지침을 전체적으로 분석한 이유는, 독일의 장애인 체육 지도자 과정은 '생활체육 지도자 과정,' ‘예방체육 지도자 과정,'

‘엘리트 체육 지도자 과정,' 그리고 본 연구에서 초점을 두고 있는 '재활체육 지도자 과정 '으로 구분하고 모든 교육 시스템이 모듈식 구조를 갖추고 유기적으로 연계되어 전체적인 교육 시스템의 이해가 없이는 재활체육 지도자 과정의 이해가 어렵기 때문이다.

본 연구는 2020년 현재의 ·독일장애인체육협회 연수 교육 지침서[4](2018년 7월 14일에 개정)' 의 총체적 분석, 독일장애인체육협회 웹사이트상의 다양한 자료 분석과 독일장애인체육협회의 '교육 학습 담당자' 와의 심층 인터뷰로 진행하였다. 독일장애인체육협회의 현장 관계자 3명과 '독일장애인체육협회 연수 교육 지침서' 를 바탕으로 구조화된 개방형 질문지를 활용하여 코로나 $19(\mathrm{COVID}-19)$ 로 전화 인터뷰를 진행하였다. 개방형 설문 문항은 특수체육전공교수 1 인, 특수체육 현장 전문가 1 인으로부터 문항의 타당도를 검증받았다. 인터뷰 문항은 크게 (1) '독일 장애인 체육 교육의 기본 방향' 과 '독일 재활 체육 교육의 기본 방향' (2) 모듈식 지도자 교육 시스템 (3) 재활체육 지도자 교육의 목표 그리고 (4) 교육과정의 내용, 시험 및 라이센스 규정으로 구성되었다.

\section{2. 국내 재활체육 지도자 교육의 상황}

독일 재활체육은 세계대전 이후 상이군인들의 재활을 위하여 시작되었고 우리나라도 한국전쟁과 월남 파병 상이군인들의 치료 목적으로 시작되었다는 점에서 공통점이 있다고 할 수 있다. 이러한 공통점에도 불구하고 우리나라의 재활체육의 발전은 독일보다 매우 늦다고 할 수 있다.

행정체계를 보면, 우리나라는 재활체육과 장애인체육을 보건복지부와 문화관광체육부가 분담하고 있다. 문화관광체육부는 장애인 엘리트 선수 양성이나 생활체육 관련 업무를 담당하고 보건복지부는 재활스포츠 업무를 담당하고 있다. 따라서 긴밀한 협업이 요구되고 향후 부처의 통일이 필요할 수도 있을 것이다.

재활체육은 2005년 장애인체육재활체육에 관한 업무가 한국장애인개발원의 업무가 되고, 장애인 엘리트 선수 양성 및 장애인체육 업무는 대한장애인체육회로 이관되면서 
본격적으로 시작되었다.

재활체육은 장애인복지법 제 58 조와 시행규칙 제 41 조를 바탕으로, 장애인체육시설에서 장애인들이 체력증진, 여가활동 또는 사회참여 활동을 위해 프로그램 등을 이용할 수 있는 것이다. 그러나 국내 재활체육의 개념 및 역할 탐색과 장애인체육과 재활체육 연계방안을 제시한 노형규와 이동철(2016)에 의하면, 2010년 이후 한동안은 재활체육과 관련된 연구가 잘 이루어지지 않고 있으며 관심도 줄어들었다는 것을 알 수 있다[5]. 우리나라에서 그동안 재활체육에의 발전을 위한 노력을 하지 않은 것은 아니다. 보건복지부는 재활체육의 발전을 위해 한국장애인개발원을 재활체육의 진흥을 위한 기관으로 지정하였고 문화체육관광부 산하의 대한장애인체육회를 중심으로 장애인 생활체육 사업을 진행해 오면서 재활체육에 대한 노력도 이어왔다[6]. 또한, 재활병원의 장애인건강증진센터 재활체육관에서도 재활체육 프로그램을 꾸준히 제공해 왔다. 그러나 재활체육 전문지도자 양성과정은 아직도 개발되지 않고 있으며, 시설과 프로그램의 개발은 여전히 부족한 현실이다. 그러나 최근 '장애인건강권법' 으로 재활체육의 활성화가 다시금 기대되고 있다.

한편, 우리나라는 재활 스포츠에 대한 법적인 정의가 확실하지는 않다. 장애인건강권법에서의 “재활운동 및 체육” 이 실제로 재활체육이라고 하기에는 다소 무리가 있는 것이다.체육의 경우 국민체육진흥법을 따라야 하는 반면, 재활운동의 경우 체육 분야와 협업과 함께 보건의료분야에 포함된다.

전문 지도자 양성과정의 경우, 우리나라에서 장애인 체육과 관련된 자격증으로는 교육과학기술부의 특수학교 체육 정교사 교원자격과 문화관광 체육부에서 시행하는 장애인스포츠지도사 자격증이 있다. 이 중 장애인 스포츠 지도자의 경우에는 1 급과 2 급 자격이 있으며 장애인들의 특성에 맞추어 감각이나 지각운동뿐 아니라 체력운동과 기본운동기술, 종목별 스포츠 기술을 지도한다[7]. 장애인스포츠지도사 자격의 경우 연수과정 중 장애특성을 이해하고 이에 따른 스포츠지도가 이루어질 수 있도록 교육하고 있으나 실제로는 장애인을 대상으로 한 스포츠 종목을 가르치는 즉, 생활체육을 가르치는 전문가의 양성과정이라고 할 수 있다. 독일의 재활 스포츠와 달리, 재활의 최종 목표라고 할 수 있는 '사회복귀' 를 위한 교육은 이루어지지 않고 있고 따라서 재활체육을 위한 전문가의 양성이라기에는 부족한 부분이 있는 것이다. 또한 현재 장애인 스포츠지도사 자격증을 취득한 인력들의 경우에도 대부분 장애인을 지도하고 있어 장애인들에 대한 재활 체육관련 서비스를 제공할 인력은 여전히 부족한 현실이다. 홍상민 (2016)에 의하면, 장애인 생활체육지도자의 경우 2007년에는 21명이었던 반면, 2016년에는 324명이 배치되어 매우 확대되었다고 할 수 있으나 전체 인구의 $5.59 \%$ 가 장애인이라는 것을 고려하면 매우 부족하다[8]. 특히 재활체육 지도자 자격을 위한 교육과정은 아직도 만들어지지 않고 있어 이러한 부분의 연구과 시행이 시급하다고 할 수 있다.

\section{3. 독일 장애인 체육협회 교육의 기본 방향 분석}

독일의 경우, 우리나라와는 달리, 재활체육을 제공하는 기관은 다양하지만 재활체육을 제공하기 위해서는 국가의 공식적인 승인, 즉 독일 장애인 스포츠협회(DBS: Deuscher 
Behinderten Sportverband)의 승인이 필요하다. 독일장애인스포츠협회는 독일 주 정부의 재활스포츠를 담당하고 있는데 재활스포츠에 대한 가이드라인을 제시하여 각 주의 관련 기관이 이에 맞추어 지도하게 되는 것이다[9]. 따라서 '재활체육 지도자 과정' 의 교육에 대해서 이해하기 위해서는 독일 장애인 체육협회 연수 교육의 기본 방향에 대한 이해가 필요하다. 이를 위해 2018년 개정 '독일장애인체육협회 연수 교육 지침서' 를 전반적으로 분석하였다. 많은 양의 정보가 있었으나 특히 우리나라의 재활지도자 교육과정에 적용하기에 좋은 내용을 중심으로 분석을 하였다. 분석결과 가장 눈에 띄는 것 중 하나는 독일의 장애인 체육 지도자 교육 시에는 폭력, 차별, 그리고 성적 학대에 매우 엄격해야 함을 지도한다는 것을 알 수 있다. '트레이너, 지도자, 클럽 매니저들이 장애가 있거나 만성 질환이 있는 아동, 청소년 및 성인을 대할 때 어떠한 폭력, 차별 또는 성적 학대도 용납하지 않는다, 라고 하고 있다. 우리나라에서도 최근에는 폭력, 차별, 성적 학대에 대한 의식이 강해지고 있는데, 독일에서는 교육과정에서 매우 강조하고 있음을 알 수 있다.

또한 지식과 기술을 습득하는 것뿐 아니라 개인의 태도와 가치를 개발하는 것을 목표로 한다. 스포츠 교육과 스포츠를 통한 교육은 스포츠를 하는 개인에 초점을 맞추고 있는데, 다른 선수들의 존중, 책임감 있는 상호 작용, 자연 환경에 대한 존중은 성격의 발달과 형성에 중요한 요소라고 언급하고 있으며, 공동체 역량, 의사소통 역량, 목표를 향한 자신을 지향하는 능력, 계획 능력, 협력 능력, 공정성, 수행 동기, 건강 인식 등과 같은 역량을 함양하는 것을 목표로 한다. 이러한 내용은 최근 전 세계적으로 관심을 받고 있는 역량중심 교육과도 일치한다고 할 수 있다. 즉, 재활을 마친 사람들이 가정과 사회로 복귀하여 잘 어울리고 질이 높은 삶을 영유할 수 있도록 하는 것이다. 한편, 국내의 경우에는 장애인 스포츠가 생활스포츠에 한정되어 있다고 할 수 있고 이러한 사회복귀를 위한 프로그램은 매우 부족하다.

교육의 이행과 실행의 측면에서는 '성찰적 과정으로서의 교육' 을 강조하고 있다. 즉, 사람은 누군가가 교육 시키는 것이 아니고 스스로 교육된다고 하고 있다. 따라서 교육과정은 철저히 계획되는 것도 중요하지만 참여자들의 동기를 부여 할 수 있어야 할 것이다. 또한 학습 내용과 경험은 항상 개인의 경험과 관련이 있어야 한다는 것도 강조하고 있다. '평생 과정으로서의 교육' 도 강조하고 있으며 개인적, 직업적, 사회적 상황이 변할 때마다 개인은 스스로를 재정비해야 한다고 하고 있다. '역동적 과정으로서의 교육' 도 의미 있는 부분이다. 불확실성과 실수는 교육에서 불가피하다고 생각하고 있다.. 앞에서도 언급한 바와 같이 '인간관계의 다양성' 과 '성인지' 도 중요하게 생각하고 있으며, 무엇보다도 독일 교육의 대표적인 특징이라고 할 수 있는, '자연 친화적 과정으로서의 교육' 을 강조한다. 자연속의 스포츠는 자연환경에 대한 정서적, 인지적 인지를 촉진하고, 교육은 이처럼 자연에 대한 인식을 높이는 것을 목표로 해야 한다고 하고 있다. 독일의 장애인 스포츠 교육 과정에서는 자연이 스포츠 운동의 장소일 뿐만 아니라 인간과 자연의 상호 작용을 위한 공간으로 이해되도록 하고 있다. Innenmoeser(1999)는 재활체육의 효과로서 신체적 효과뿐 아니라 심리적 사회적 효과도 언급하고 있는데[10] 지침을 전반적으로 분석해 보면, 독일의 재활체육 지도자 교육과정의 방향은 이를 잘 반영하고 있음을 알 수 있었다. 우리나라에는 아직 재활체육 지도자 교육과정이 개발되지 않고 있지만 향후 개발 시 스포츠 관련 전문적 역량을 함양 
외에도 심리적 사회적인 부분도 고려해야 할 것이다.

\section{4. 모듈식 지도자 교육 시스템 분석}

독일의 경우에는 장애인 체육 지도자 과정이 본 연구에서 초점을 두고 있는 '재활체 육 지도자 과정' 으로서의 장애인체육 지도자 과정 외에도 '생활체육 지도자 과정' , ‘예방 체육지도자 과정' 그리고 '엘리트 체육 지도자 과정' 으로 구분된다. 생활체육 은 움직임에 대한 인간의 욕구 충족과 사교를 위한 것인 반면에 '재활체육' 의 목적은 심신의 기능을 회복하는 것과 사회로의 복귀를 위한 것이다[8]. Schuele(1987)와 Wegner(2001)는 장애인 체육을 재활체육, 생활체육, 엘리트체육, 특수학교 체육으로 나누 었는데 독일에서는 이러한 차이를 반영하여 지도자 과정을 구분하고, 최근에는 여기에 예방체육까지 포함한 것이다[11][12]. 우리나라의 경우, 장애인스포츠지도사는 이중 생활 체육 지도사에만 해당된다고 할 수 있다. 사실상 예방체육도 넓은 의미에서 재활체육에 포함시킬 수 있으나 본 연구에서는 이 중 '재활체육 지도자 과정' 에만 초점을 맞추고자 한다.

독일의 재활체육 전문지도자 양성과정을 정확하게 이해하기 위해서는 독일의 장애인 지도자 연수교육 시스템을 이해해야 한다. 재활체육을 포함한 장애인 교육은 독일장애인 체육협회에서 담당하고 있는데 교육과정은 4단계에 걸쳐서 이루어진다. 그러나 재활체육 교육과정이 이 4 단계로 이루어진 것은 아니고 실제적으로는 2단계라고 할 수 있다. [그림 1]을 보면, 모든 교육 시스템이 모듈식 구조를 가지고 있으며, '재활체육 지도자 과정' , '생활체육 지도자 과정' , '예방 체육 지도자 과정' 그리고'엘리트 체육 지도자 과 정' 에 관계없이 모든 지도자 과정에서 1단계인 (블록 10)인 일반적인 기초교육단계를 거 쳐야 한다. 이 과정에는 총 90 시간을 이수해야 한다(1시간=45분). 이 외에도 '재활체육 지도자 과정' 의 경우 [그림 1]과 같이 '장애 유형별 교육단계' 를 거쳐야 하는데, 정형 외과적 장애, 90 시간, 내과장애 120 시간, 감각기관장애 90 시간, 신경계장애 90 시간, 정신 장애 90 시간, 지적장애 90 시간을 추가로 이수해야 한다. 구체적으로, 정형외과적 장애의 경우에는 암 질환(15hr), 절단 및 사지손상(15hr), 골다공증(15hr)등의 장애를 포함하고, 감 각기관장애의 경우에는 시각장애( $15 \mathrm{hr})$, 중추 및 말초신경계 장애 등을 포함한다. 또한 각 장애 유형별 필수과목을 모두 이수하면 장애 유형별 인증서를 발급해 준다, 예를 들어

‘정형외과적 장애 교육 인증' 을 해 주는 것이다.

이러한 단계별 교육 외에도 '독일의 장애인 지도자 연수교육 시스템' 은 독일 장애인 전문 협회 별 업무와 장애 또는 만성 질환이 있는 모든 사람들의 대상 그룹별로 지도자 훈련 과정을 구분하여 모듈형으로 나타내고 있다는 점에서 매우 체계적이라고 할 수 있 다. 재활체육트레이너의 경우에는 트레이너 B 과정만 있으나, 엘리트 장애인 트레이너 과 정의 경우에는 $\mathrm{A}, \mathrm{B}, \mathrm{C}$ 등급으로 나뉘는데, C급의 경우에는, 낮은 수준의 엘리트스포츠에 서 장애 또는 만성 질환이 있는 사람들을 위한 운동 및 훈련 시간의 계획, 실행 및 평가 를 위한 과정이며, $\mathrm{B}$ 급은 중간 수준의 엘리트스포츠 해당하며, 이 교육과정은 $\mathrm{C}$ 급 자격 과정에서 습득 한 지식, 능력 및 숙련도를 기반으로 한다. 또한 이 교육은 상위 수준의 엘리트스포츠 해당 스포츠종목에서 장애 또는 만성 질환이 있는 사람들을 위한 운동 및 훈련 시간의 계획, 실행 및 평가를 위한 자격을 부여한다. $\mathrm{A}$ 급 자격과정은 $\mathrm{B}$ 급 지도자 
과정에서 습득 한 지식, 능력 및 숙련도를 기반으로 상위 수준의 엘리트 스포츠에 해당 된다. 이처럼 등급의 구분이 필요한 지도자 과정과 그렇지 않은 지도자 과정을 잘 구분 하여 개발하고 있었다.

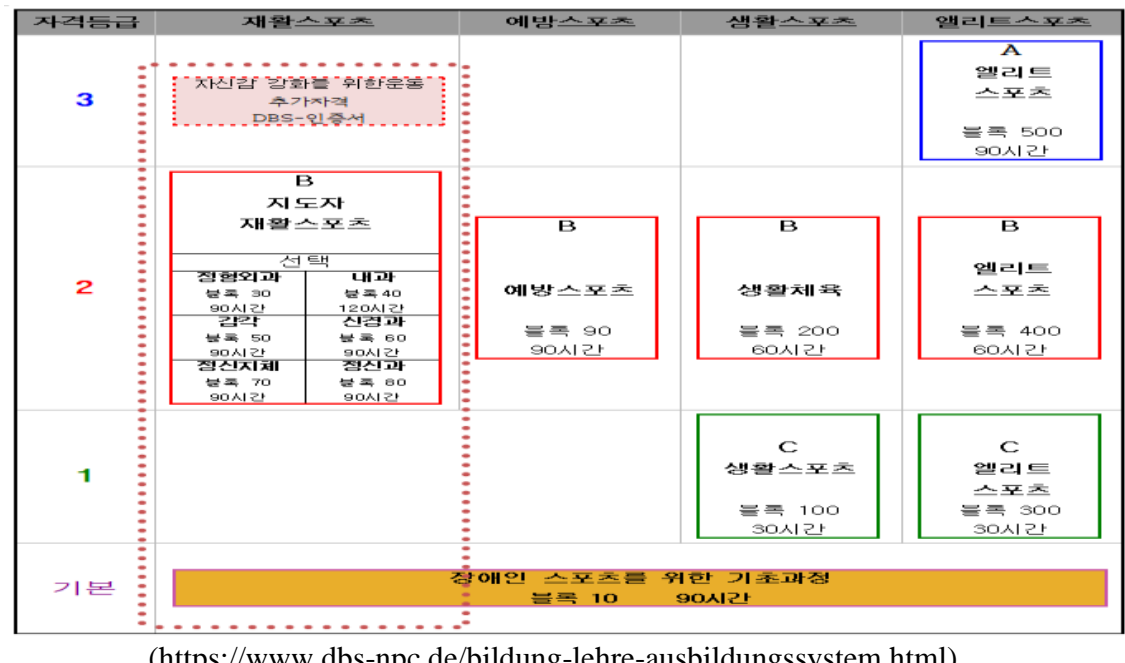

(https://www.dbs-npc.de/bildung-lehre-ausbildungssystem.html)

[그림 1] 모듈식 장애인체육 지도자 교육과정[13]

[Fig. 1] Modular Training Course for Disabled Sports Instructors[13]

과목들을 보면, 독일 재활체육은 체육과 의학이 결합되어 있음을 볼 수 있는데, 이러한 이유로 대상자들이 의료보험 혜택 등의 지원을 받을 수 있다는 점도 의미가 있다고 할 수 있다. 우리나라의 경우에 재활스포츠의 혜택이 적은 것과 대조적이라고 할 수 있다.

\section{5. 재활체육 지도자 교육의 목표 분석}

모든 연수나 교육의 과정에서는 목표가 중요하므로, 본 장에서는 독일의 재활체육 전문 지도자 연수교육과정에서 지도자 과정을 이수한 후의 지도가자 갖추어야 할 능력의 목표에 대해서 구체적으로 분석해 보고자 한다. 목표는 크게 개인적, 사회적 의사소통 능력, 전문적 역량, 교수 방법 및 전달 역량으로 구분하는데 내용 지식 뿐 아니라 사회적 의사소통 능력이나 교수방법에 대한 능력도 중요하게 생각한다는 특징이 있다. 우리나라에는 아직 재활체육 지도자 교육과정은 개발이 되지 않았지만 특수체육교육과정을 보면, 최근에 이와 비슷하게 의사소통 능력이나 교수방법을 독일과 같이 중요하게 생각함을 알 수 있다.

먼저 개인적, 사회적 의사소통 능력을 보면, 재활체육 전문지도자는 개인적, 사회적 의사소통 능력 목표는 질병에 대처할 수 있는 스포츠의 잠재력을 알고 이를 실천할 수 있으며 또한 개인 생활 상황과 관련하여 해당자의 신상에 대한 질병 또는 장애의 가능한 효과를 알고, 이를 적절하게 고려할 수 있어야 한다는 것이다. 또한 참가자 개인의 스트레스나 부담 상황을 인식하고 적절하게 대처할 수 있어야 한다. 즉, 참가자에 대한 이해를 중요하게 생각하고 있다. 이는 모든 스포츠지도자에게 요구되는 능력에 해당 되겠지만 장애를 가지고 있는 참가자들에게는 특히 요구될 것으로 사료된다. 이 외에도 
분쟁을 포함한 다양한 상황에서 대화의 기술을 적절하게 사용할 수 있어야 하는 것은 물론이고 참가들이 건강한 생활을 할 수 있도록 조언하고 지원해야 한다. 또한 참가자의 개인적 발전에 기여할 수 있어야 한다. 이러한 능력을 갖추도록 하는 것은 재활체육 지도자가 재활교육을 받는 순간 뿐 아니라 자기주도적으로 관리를 할 수 있도록 도울 수 있다는 점에서 의의가 있다. 독일은 체육과 건강증진활동을 통해 장애인들이 잠재력을 발휘하고 변화와 성장을 이룰 수 있는 것을 목표로 하고 있다는 것을 잘 보여주고 있는 부분이다.

전문적 역량 또한 중요하게 생각하고 있는데, 재활체육 전문지도자는 재활 스포츠의 중요성과 목표는 물론, 관련 신체 및 기관들의 해부학적 또는 생리학적 지식이 있어야 한다. 이 외에도 질병 관련된 변화, 진단 절차 및 치료와 조치 방법에 대해 알고 있으며 신체 활동에 미치는 영향을 고려할 수 있어야 하며 징후별 퇴행성 변화를 알고 있어야 한다. 위험 및 비상 상황을 즉시 인식 할 수 있어야 하고 심폐 소생술이 가능해야 한다. 또한 재활 스포츠 그룹을 분류 할 수 있어야 하며 그룹 관리가 가능해야 한다. 우리나라에서 재활체육지도자 교육과정을 개발할 때에 적용할 수 있는 부분일 것이다.

교육방법 및 전달 능력의 측면에서는, 지도자는 다양한 의사소통 방법과 스포츠 및 운동 제안에서 가능한 응용 프로그램을 알고 있으며 참가자가 장기 행동 변화가 가능하도록 중장기 계획을 세울 수 있어야 한다. 중립적이고 이해하기 쉬운 언어로 정보를 전달할 수 있는 능력이 있어야 함은 물론이고, 건강 증진 조치, 예를 들면 영양 조언이나 라이프 스타일 조언 등을 할 수 있으며 이를 운동 수업에 포함하거나 구성 할 수 있어야 한다. 이러한 목표는 우리나라의 스포츠 지도자나 체육교사에게 요구되는 것과 공통되는 부분도 많지만, 추가로 적용할 것도 있다는 것을 알 수 있다.

\section{6. 교육과정의 내용, 시험 및 라이센스 규정 분석}

위에서 독일의 장애인 체육 지도자 과정은 모듈식 구조를 가지고 있으며, '재활체육 지도자 과정', '생활체육 지도자 과정' , '예방 체육 지도자 과정' 그리고 '엘리트 체육 지도자 과정' 에 관계없이 모든 지도자 과정에서 1 단계인 (블록 10)인 일반적인 기초교육단계를 거쳐야 한다고 하였는데, 기초교육과정에는 교수법이나 방법론 과목은 물론이고, 영양학이나 심리학과 사회학, 참관과 실습이 포함되어 있음을 알 수 있다.

시험의 경우 합격의 기준이 연수 시작 시 공개되어 성취기준을 확실히 알 수 있도록 하는데, 전체 교육 기간 동안 적극적인 참여, 실연 능력 증명, 그룹 작업 결과 발표, 운동 수업 계획, 실행 및 반영, 관찰과 참여 등이 포함되어 이론 보다는 실제 지도 수행 능력에 초점을 맞추고 있고 공동체 역량 등도 평가함을 알 수 있다.

라이센스를 취득하려면 지도능력이 증명되어야 하는데 이 라이센스는 유효기간이 있다. 유효 기간은 최대 4 년 또는 내과 분야에서는 최대 2 년이고 자격보유자가 관련 법령, 규정 또는 조항을 위반할 경우 라이센스를 철회 할 수 있다. 또한 자격증 취득으로 학습 과정이 완료된 것은 아니고 정기적인 재교육이 필요하다. 이는 최신의 정보를 배울 수 있고 배운 지식, 기술 및 능력을 보완하고 심화할 수 있다는 점에서 그 의의가 있다. 우리나라에는 아직 재활체육 지도자 교육과정은 개발되지 않고 있지만 타 생활체육 지도자 과정을 보면 재교육이 없는데 이러한 재교육은 필요할 것으로 사료된다. 
의학적 검진결과를 바탕으로 운동을 지도하도록 하여 의학분야에 더 관련이 있고 장애인 스포츠지도사는 생활체육 지도사에 가깝다고 할 수 있는데, 우리나라에도 전문적인 '장애인 재활체육 전문 지도자' 양성 과정과 자격제도의 개발 필요하다. 또한 이후에는 지금까지는 고려하지 않고 있는 '예방 체육 지도자' 양성 과정과 자격제도의 신설도 필요할 것이다.

둘째, 독일의 재활체육 전문 지도자에게 요구되는 역량은 목표 분석에서 알 수 있었는데 요구되는 역량은 크게 개인적, 사회적 의사소통 능력, 전문적 역량, 교수 방법 및 전달 역량으로 구분되었다. 내용 지식 뿐 아니라 사회적 의사소통 능력이나 교수방법에 대한 능력도 중요하게 생각한다는 특징이 있었다. 우리나라의 재활체육 지도자 교육과정을 개발한다면, 개발 초기부터 체육 관련 지식이나 해부학적 지식 등 전문적 역량 외에도 사회적 의사소통 능력이나 교수 방법 및 전달 역량을 함양할 수 있는 교육을 포함해야 할 것이다. 예를 들면, 의사소통을 도울 수 있는 교과목을 포함시키거나 평가의 기준에도 포함해야 할 것이다.

셋째, 교육과정에는 교수법이나 방법론 과목은 물론이고, 영양학이나 심리학과 사회학, 참관과 실습이 포함되어 있음을 알 수 있다. 시험의 경우 전체 교육 기간 동안 적극적인 참여, 실연 능력 증명, 그룹 작업 결과 발표, 운동 수업 계획, 실행 및 반영, 관찰과 참여 등이 포함되어 실제 지도 수행 능력에 초점을 맞추어 평가함을 알 수 있었다. 또한 라이센스는 유효기간이 있을 뿐 아니라 정기적인 재교육을 통해 최신의 정보를 배울 수 있고 배운 지식, 기술 및 능력을 보완하고 심화할 수 있도록 하였다.

우리나라의 재활체육 전문 지도자 자격제도 개발 시에는 목표에 적합한 평가 방법을 제시하고 이처럼 수행평가 즉 실제 가르치는 능력을 평가해야 할 것이다. 또한 우리나라의 타 스포츠지도자 자격증 제도를 보면 재교육을 통한 업그레이드 기회도 제공이 부족한데, 이러한 기회의 제공 또한 필요할 것이다.

넷째, 독일은 '성찰적 과정으로서의 교육' 을 강조하고 있었다. 즉, 사람은 누군가가 교육 시키는 것이 아니고 스스로 교육 되어 진다고 하고 있다. '평생 과정으로서의 교육, 등도 중요시함을 알 수 있었다. 따라서 재활체육 과정을 마치게 되면 재활 체육 이후의 지속적인 체육활동의 동기가 부여될 수도 있는 것이다. 우리나라의 교육과정에도 재활 교육을 통해 스스로 변화와 성장을 할 수 있는 힘을 길러주는 교육이 가능하도록 해야 할 것이다.

장애인 재활체육의 발전을 위해서는 장애인 체육 전문 지도자 양성 과정과 자격제도 신설이 선제적으로 필요하고 이를 뒷받침 할 수 있는 제도적 차원의 지원이 필요할 것이다. 우리나라에서도 '장애인건강권법' 으로 제도가 마련되기 시작하고 있으므로, 향후 지속적인 지원과 구체적 실행을 위한 후속연구가 많이 이루어져 독일의 재활체육과 같이 발전할 수 있기를 기대한다.

본 연구는 실제 재활체육지도자 과정의 개발 시 포함되거나 고려되어야 할 내용을 전반적으로 포함하고 있다는 점에서 의의가 있으나 우리나라 실정에 적합한지에 대한 연구는 부족하다는 한계가 있다. 적합성 여부에 대한 후속연구가 필요할 것으로 사료된다. 


\section{References}

[1] K. S. Kim, C. K. Kim, G. I. Lee, J. H. Lee, I. K. Jung, Development of rehabilitation sports program for people with mild mental retardation and spinal cord disabilities, Korea Welfare Promotion Association for the Disabled, (2006)

[2] Y. T. Suh, Korea Disabled People's Development of rehabilitation sports program for people with cerebral palsy, Discussion meeting to seek ways to develop rehabilitation sports for the disabled, Development Institute, (2008)

[3] H. Yoo, A Study on the Policy of Rehabilitation Sports and the Curriculum of Trainer Course in Germany, Journal of Sport and Leisure Studies, (2011), Vol.43, No.2, pp.1093-1102.

[4] Deutscher Behindertensportverband e.V., Richtlinien für die Ausbildung im Deutschen Behindertensportverband e.V., Frechen-Buschbell, (2018)

[5] H. K. Roh, D. C. Lee, Study on Exploring the Role of Rehabilitation Physical Activity and Connected Planning Adapted Physical Activity, Journal of adapted physical activity and exercise, (2016), Vol.24, No.1, pp.53-70.

[6] A study on institutionalization of rehabilitation sports, Seoul: Korea Disabled People's Development Institute, (2010)

[7] B. D. Park, S. Y. Beak, K. I. Kim, The Exploring for Cultivating Possibility to Adapted Physical Educator by Reorganization on National Sports Instructor, Journal of Adapted Physical Activity and Exercise, (2013), Vol.21, No.4, pp.27-39.

[8] S. M. Hong, The Needs and Development Plans of Sports/Exercise Specialist for the Disabled, Journal of Adapted Physical Activity and Exercise, (2016), No.24, Vol.2, pp.67-75.

[9] Bundesarbeitsgemeischaft fuer Rehabiltation, Rahmenvereinbarung fuer den Rehabilitationssport und das Funktionstraining, (2010)

[10] J. Innenmoser, Schwepunktthema: "Rehabilitation, Rehabilitationssport und Behinertensport, Gemeimsame Aufgaben und Ziele! Unterschiedliche Wertigkeiten?”, Koeln, Sport und Buch Strass, (1999)

[11] K. Schuele, Effektivitaet und Effizienz in der Rehabilitation, St. Augustin Verlag: Hans Richarz, (1987)

[12] M. Wegner, Sport und Behinderung: zur Psychologie der Belastungsverarbeitung im Spiegel von Einzelfallanalysen, 1. Aufl. Hofmann, (2001)

[13] Deutscher Behindertensportverband, https://www.dbs-npc.de/bildung-lehre-ausbildungssystem.html, (2020) 